\title{
Acceptability and Impact of Group Interpersonal Therapy (IPT-G) on Kenyan Adolescent Mothers Living with HIV: A Qualitative Analysis
}

\section{Obadia Yator}

University of Nairobi

Lincoln Khasakhala

University of Nairobi

Grace John Stewart

University of Washington Seattle Campus: University of Washington

Manasi Kumar ( $\square$ manni_3in@hotmail.com )

University of Nairobi https://orcid.org/0000-0002-9773-8014

\section{Primary research}

Keywords: Task shifting, postpartum depression, HIV-related stigma, Group Interpersonal psychotherapy, community health volunteers

Posted Date: October 22nd, 2020

DOl: https://doi.org/10.21203/rs.3.rs-93468/v1

License: (9) This work is licensed under a Creative Commons Attribution 4.0 International License. Read Full License 


\section{Abstract}

Background Task shifting is a well-tested implementation strategy, within low- and middle-income countries (LMICs), that addresses the shortage of trained mental health personnel. Task sharing can increase access to care for patients with mental illnesses. In Kenya, community health workers [CHWs are a combination of community health assistants (CHAs) and community health volunteers (CHVs)], have played a crucial role in this front. In our study, we seek to assess the acceptability and feasibility of IPT-G delivered by CHWs among depressed postpartum adolescents (PPAs) living with HIV.

Method Twenty-four PPAs were administered IPT-G by trained CHWs from two health centers. A two-arm study design (IPT-G intervention and treatment as usual) with an intent to treat was used to assess acceptability and feasibility of IPT-G. Participants who scored $>10$ on Edinburgh postnatal depression scale (EPDS) and who were 6-12 weeks postpartum were eligible for the study using purposeful sampling. Participants were equally distributed into two groups: one group for intervention and another for wait-list group. This was achieved by randomly allocating numerical numbers and separating those with odd numbers (intervention group) and even numbers (wait-list group). Focus group discussions (FGDs) and in-depth interviews ascertained the experience and perceptions of the postpartum adolescents and the CHWs. In addition to weekly face-to-face continuous supportive supervision for CHWs, phone calls, short messages services, and WhatsApp instant messaging services were also utilized.

Results The CHWs found the intervention useful for their own knowledge and skill-set. On participation, 21 out of the 24 adolescents attended all sessions. Most of the adolescents reported improvement in their interpersonal relationships with reduced distress and lessening of HIV-related stigma. Primary health care workers embraced the intervention by availing space for sessions.

Conclusion Our study demonstrates possible benefits of task shifting in addressing mental health problems within low-resource settings in Kenya and group IPT is demonstrated to be both acceptable and feasible by health workers and adolescents receiving care.

\section{Background}

\section{Shortage of mental health personnel and associated challenges}

Chronic shortage of well-trained health personnel in Sub-Saharan Africa (SSA) necessitated task shifting as a key implementation strategy. Task shifting in SSA health systems typically mean CHWs are trained to help increase number of health services being provided to reduce cost and improve delivery of care (WHO, 2007). The concept of task shifting involves rational distribution from well-trained to less specialized health workers or those who have been trained on a limited time duration on specific skills in a given area of need (WHO, 2006). Several barriers to task shifting revolve around the need to strengthen health systems by improving systemic and physical structures (Dawson et al., 2014). CHWs undergo challenging experiences while task-shifting: undertaking tasks that may drain them emotionally and 
physically, persistent problems of inadequate training, unstructured supervision, and poor remuneration or complete lack of reward or entitlements to any form of benefit in some instances (Mundeva et al., 2018).

Task shifting is meant to reduce workloads for overburdened specialist health workers and improve patients' linkage to services (Mwai et al., 2013). In Kenya, CHWs are not well compensated and sometimes expected to work on voluntary basis with poorly structured responsibilities causing them to take roles requiring more skills than their abilities (Angwenyi et al., 2013). Embracing task shifting of key preventive and promotive activities in the HIV program using CHWs promises to be a good step towards achieving the 90-90-90 goals. UNAIDS, too, has identified the engagement of community workers as essential in HIV prevention and advocacy (UNAIDS and Stop AIDS Alliance, 2015).

\section{Prevalence of HIV in peripartum adolescents in Kenya}

Our study is targeting one of the most vulnerable youth populations: adolescent mothers living with HIV. In SSA, adolescent girls aged 15-24 years represent $10 \%$ of the population, and using 2017 estimates, this group accounts for $25 \%$ of the new HIV infections (UNAIDS, 2018). The prevalence of HIV in Kenya among female adolescents aged $15-24$ is $4 \%$ (NACC, 2016), and these young girls are two times more likely to contract HIV than their male counterparts (NASCOP - Kenya, 2016).

The overall prevalence of adolescent pregnancy in Africa is $18.8 \%$ and $19.3 \%$ for the Sub-Saharan region (Kassa, Arowojolu, Odukogbe, \& Yalew, 2018). By the age of 18, $42 \%$ of adolescents from SSA living in urban areas will have become pregnant, and more than $50 \%$ of their rural counterparts would be so (UNAIDS, 2019). This early pregnancy also increases their chances of HIV infections (Christofides et al., 2014). Most adolescents are seen to be infected with HIV by older men aged late 20 s and early 30 s who may not even be aware of their status and thus, unlikely to be on anti-retroviral therapy (ART) (de Oliveira et al., 2017).

A study in Malawi found that adolescents living with HIV had a depression prevalence of $18.9 \%$ (Kim et al., 2014). A similar study in Kenya focusing on mental health outcomes among adolescents living with HIV documented almost same depression prevalence of 17.8\% (Kamau et al., 2012). Worldwide, postpartum depression (PPD) prevalence in adolescents is higher than that for adults, and it is estimated to range from 26-50\% (Dinwiddie et al., 2018; Nunes \& Phipps, 2013; Sangsawang et al., 2019; Torres et al., 2017).

\section{Role of psychosocial interventions for adolescents}

Psychological interventions have been recommended for persons living with HIV to mitigate common mental health illnesses, including depressive illnesses (Sherr et al., 2011), with no side effects against ART (Cruess et al., 2003). Psychological interventions for adolescents should aim at addressing issues related to psychosocial development, training on social skills including life skills, and shaping their behaviors towards a future productive life through livelihood and vocational training (Martinez et al., 
2014). It has been found that adolescents have significant risks of frequent unprotected sex with an equally high risk of contracting HIV and having an unplanned pregnancy or both at some time (Schunter et al., 2014). Adolescents engage in risk-taking behaviors and girls may be less assertive to negotiate for condoms; hence, higher chances of unprotected sex are serious considerations (Januraga et al., 2014) in trying to address well-being of adolescent girls.

Prevention of mother-to-child transmission clinic (PMTCT) has provided a conducive environment for addressing life challenges associated with HIV infection among perinatal women. In the year 2017, global ART coverage among men aged 15 years and above was $53 \%$ compared with $65 \%$ of women for the same age (UNAIDS, 2018). In a recent study from six sub-Saharan countries, HIV-related stigma has been associated with delays in treatment and difficulties in adhering to ART, as shown in systematic review studies (Ammon et al., 2018; Croome et al., 2017). An emerging finding of note is that depression treatment improves adherence to ART, which is key to improved quality of life (Sin \& DiMatteo, 2014; Wagner et al., 2020).

A Nigerian study on psychological intervention for adolescents living with HIV utilized support groups using Facebook groups for a 5-weekly session. The ability for adolescents to interact, learn more about HIV, share experiences, and their fears on social media was seen to help them in coping with their status (Dulli et al., 2018).

\section{Group Interpersonal Psychotherapy (IPT-G) and its relevance for this vulnerable population}

A study assessed interpersonal relationships between youth and their families and found out that poor relationships led to depression (Okawa et al., 2018). Lower caregiver supervision was also associated with higher depression (Bhana et al., 2016). IPT-G is well-poised to help address interpersonal difficulties that adolescents are predisposed to. It is conceptualized around four problem areas: grief and loss, interpersonal role disputes, role transitions, and interpersonal deficits/social isolation. During adaptation of IPT-G for depressed adolescents, Mufson et al (2004) reported that the intervention targets an individual's interpersonal relations with other persons in a given family/society where therapeutic benefits are achieved (Mufson et al., 2004). For example, when postpartum adolescents living with HIV are put together in a therapy session, they appreciate that their unpleasant experiences in life also affect other persons in similar situations. This motivates the adolescent to try new interpersonal interactions that enhance better social functioning in society. IPT-G provides adolescents with peers who have similar difficulties and utilizes synergies in groups to understand their interpersonal problems and develop new ways of coping.

Our study is in line with a call by WHO to embrace strengthening of Universal Health coverage. Primary health care depends on health system structures acknowledging various levels of health care services where specialized health workers are deployed at the referral levels and $\mathrm{CHWs}$ are based at the community level and both are interdependent (Ministry of Health, 2020; WHO-Unicef, 1978; WHO, 2017).

We aim to assess qualitatively the acceptability and feasibility of IPT-G for postpartum adolescents living with HIV being delivered by CHWs within routine clinical settings in Nairobi, Kenya. 


\section{Method}

\section{Study design, participants, setting, and approvals}

Acceptability and feasibility of IPT-G when delivered by a non-medical specialist in routine clinical settings was assessed. We conducted our intervention between August 2018 and July 2019. Twenty-four postpartum adolescents (PPAs) aged 15-24 years and living with HIV were recruited from two sites: Kangemi health center and Kariobangi health center. They were also expected to be 6-12 weeks postpartum. The two study sites were chosen since it is situated on the two opposite poles of Nairobi city, and both are home to a population of low economic status. $\mathrm{CHWs}$ included $\mathrm{CHAs},(n=2)$, and $\mathrm{CHVs},(n=6)$ delivered IPT-G to PPAs. Both study sites had same numbers of CHWs.

Ethical approval was attained from Kenyatta National Hospital-University of Nairobi Ethics and Research Committee (Approval No. P97/02/2018). Thereafter, Nairobi county health services were informed of the intent to conduct the study. The health management team at all levels were ready to support the study since it was understood to be targeting a specific population known to have myriad psychosocial issues.

\section{Training and supervision of CHWs}

CHWs undertook a two-day training on IPT-G with extensive sessions of roleplays and with provision of continuous supervision. Six (6) PPAs who scored above 10 on Edinburgh Postnatal Depression scale (EPDS) were recruited for piloting IPT-G. Continuous supportive supervision to the $\mathrm{CHWs}$ was undertaken by the lead researcher, clinical supervisor, a student in her final year pursuing Masters of Science in Clinical Psychology, and a research assistant who helped oversee the recruitment of participants. A WhatsApp group for the CHWs was formed to ease communication and coordination during the study period.

\section{Sampling and recruitment of participants}

Participants who had EPDS scores $>10$ were eligible for the study. A total of forty-six (46) postpartum adolescents were screened at the PMTCT clinic, and thirty-two (32) of them made the inclusion criteria, of which twenty-five (25) consented to receive the intervention. Postpartum adolescents were given randomly allocated numerical numbers from $0-25$, and after that, odd numbers were picked for intervention group $(n=13)$, and even numbers picked for waitlist group $(n=12)$. One participant from the intervention group dropped out at the initiation of IPT-G, leaving twenty-four to proceed to completion of the study. Intervention group initiated IPT-G to completion within 8 weeks, and then the waitlist group was introduced to IPT-G. When IPT-G was being delivered, assessments for various changes were conducted at baseline, during intervention, post-intervention, and at four-month follow-up. CHWs delivered IPT-G to the two groups weekly for eight sessions per the WHO protocol (WHO \& Columbia, 2016).

\section{Data collection tools}


Screening for depressive symptoms was carried out using EPDS (Cox et al., 1987) to monitor change in scores following IPT-G intervention. Interpersonal inventory was used to assess the interpersonal relations (emotional attachments and social interaction) among the PPAs. IPT Knowledge test with 15 questions with a maximum score of 30 was used to assess CHWs skills and performance. If $70 \%$ of the items (21 points) are answered correctly, it affirms competence of an IPT practitioner.

Acceptability and feasibility of IPT-G delivered by CHWs was assessed through FGDs among PPA $(n=19)$ and $\mathrm{CHWs}(\mathrm{n}=7)$ for them to share their experiences and perception about IPT-G. In-depth interviews were conducted with the medical staff within the two sites: nursing officer-in-charge $(n=2)$, mentor-mother $(n=2)$, and CHAs $(n=2)$. The audio was recorded for all sessions to enable auditing of each weekly session as they progress to improve therapy quality. Field notes were kept during every session to document observations, experiences, and perceptions of CHWs, PPA, and other health staff within the facility (see Table 1).

\section{Data analytic approach}

Transcription of audio-recorded qualitative data and field notes were coded to identify common emerging themes highlighting barriers and facilitators of IPT-G. We conducted FGDs for CHWs and PPAs who had participated in the study and in-depth interviews for CHAs and health care management staff within the two health centers to understand their experiences and perceptions (McCain, 1988). Finally, we determined feasibility by evaluating the recruitment process, weekly observations during sessions, and completion rate of the intervention session whereas acceptability was determined by inquiring how individual participants felt about the intervention, participant's knowledge, perceptions, barriers, and gains achieved from the intervention(Sekhon et al., 2017). (See Table 2).

\section{Results}

Among the 24 participants, the majority $(21,87.5 \%)$ were aged between $21-24$ years and were mostly residing with their partners $(17,70.8 \%)$ with parity of less than 2 children $(20,83.3 \%)$. About half had attained secondary and above education level (despite unemployment ranking high at $79.2 \%$ ), and with most of them earning less than 100 USD per month (22,91.7\%) (see Table 1 ).

\section{Qualitative acceptability and feasibility data}

CHWs found the intervention useful in terms of how the intervention built their knowledge and skills and successfully delivered IPT-G. During the training of lay health workers, we found that they demonstrated a good understanding of depression and reported competency in delivering IPT-G. The adolescent mothers benefited from the IPT-G as they narrated how they could now function better, communicate better with their families and partners, interact socially, manage their anger, and even resume work for an income or education (see Table 3). 
Our adolescent participants acknowledged that IPT-G helped alleviate social isolation, anger, hopelessness, and low mood, which are typical depressive symptoms. After IPT-G intervention, our adolescent participants can now acknowledge they lived with horrible thoughts and a feeling of hopelessness around their past and felt liberated and at great ease with their new situation. They narrated how they were able to socialize with others and perform their family responsibilities effectively, including looking after the baby without negative self-perceived stigma despite them living with HIV (see Table 4).

The study had a retention and follow-up rate of 21 (87.5\%) out of the 24 . Among the $8 \mathrm{CHWs}$ recruited to deliver IPT-G, one of the CHV unfortunately suddenly passed away though remaining $7 \mathrm{CHVs}$ who participated successfully completed the delivery of intervention. One of the CHA from Kangemi health center stated that the IPT-G delivery process was workable considering it was held weekly; hence that sort of time allocation was possible (see Table 5).

Capacity building through a collaborative care approach was used, which involved engaging Director of Mental Health Services and cascading the partnership along the health care management team downwards to the level of $\mathrm{CHWs}$. The entire health management team was very supportive of our intent by issuing us with clearance and linking us to all the relevant clinical staff (See Figure 1).

\section{Pre and post IPT-G changes observed}

In both study sites, there was a shortage of trained mental health personnel. Kangemi health center has only one nurse in training under sponsorship of a non-governmental organization. In Kariobangi health center, there are only two health care workers with post-diploma training in psychiatry. There was no mental health designated space, and counselors under HIV testing services (HTS) were operating in mobile tents. After our study, most health care providers within the two health centers had appreciated the impact of IPT-G on adolescents attending prevention of mother-to-child transmission clinic (PMTCT), citing improved social functioning, better communication, and appealing personal hygiene/grooming by the adolescent mothers.

\section{Training of CHWs on IPT-G}

Screening questionnaires were administered to $\mathrm{CHWs}$ before training to assess their knowledge around mental health concepts, such as stress and depression. They all demonstrated a fair understanding of the difference between these. The CHWs appreciated continuous supportive supervision, and they felt that all their concerns arising from weekly sessions were being addressed promptly and adequately. Furthermore, it was very encouraging to hear from the $\mathrm{CHWs}$ that our participants after intervention became role models in the community by imparting skills of managing their day to day issues of life (see table 5).

The loss of one of the CHVs emotionally affected most of our participants, and it could be because he was youthful and could easily identify with him during subsequent sessions. The lead researcher, clinical 
supervisor, and research assistant organized a loss and grief therapy session for the group (adolescents and $\mathrm{CHWs}$ ) using one of the IPT problem areas. We also visited the family and arranged for tree planting within the facility, whereby family members and clinical staff where invited for the function, as a means of bringing closure for all who knew the deceased CHV. We notified the ethics office of the incident, which was documented in our protocol.

\section{Discussion}

CHWs found the intervention useful in addition to their existing knowledge and skills and were able to deliver IPT-G successfully. Our research team found that through task shifting, IPT-G can be disseminated to other adolescents in similar settings so long as recommended by WHO, training and continuous supervision of CHWs is upheld (WHO, 2007). We can now embrace findings from other studies where nonspecialist (CHWs) can be trained on specific skills to deliver an intervention with similar effectiveness just like when being delivered by specialists in mental health (Kredo et al., 2014; Murray et al., 2017). In cognizance of Universal Health Care, we too lend our voice towards the need to consider CHWs to be involved in mental health care delivery to cover for the shortage of trained mental health specialist (Ministry of Health, 2020). The CHWs were very satisfied with their achievements, and some shared their experiences on the milestones towards IPT-G delivery:

"At the beginning of the sessions, there were challenges because all the people were still new, so it is later that people came to know each other and developed trust in the group and everyone could say all her issues". (SK, age 50, Kariobangi)

The intervention empowered some of the adolescent mothers to help others, which was one of our intended purpose towards disseminating benefits to the community level.:

"Even the sessions were very good; because some used to come and tell you, I have this and that problem and I passed through this, but I went and did what you told me, and I have succeeded, you get it? One member in our group, I recall, and even at the moment, she normally rings me and tells me, that thing helped me, and I am able to help others'." (NG, age 43, Kangemi)

The IPT-G sessions formed part of the entry point to enlarging the scope of their social support and even after the intervention they continued to share their issues:

"So, it was a very big problem at the beginning, but I am glad that as the sessions were proceeding, we became good friends; actually, we developed a rapport, and even until now, some still call 'when are we meeting again?' [Laughter] --." (EO, age 24, Kariobangi)

Others were of the view that follow-up is of importance because most of the participants open-up to their issues at the middle of the sessions:

"What I can say; when I joined- let me talk about group two, we came well but after attending like three sessions is when you could see them now pouring out [Laughter] they tell you all their troubles in life- -." 
(FC, age 30, Kangemi)

The CHWs were now able to connect easily with the adolescent mothers after bonding with them during the sessions:

"So, we are also still doing follow-ups. Some even call by themselves, sometimes I call them, some even when they come for clinics, they just come looking for us which is good so, so they trust us. So, there is that trust, there is that friendship, there are so many benefits that came out of this, so I was just gladly sharing." (EO, age 24, Kariobangi)

Our adolescent participants benefited from the IPT-G as they narrated how they could now communicate, interact with others, manage their anger, and even resume work for an income. It is worth noting that in a study that assessed interpersonal relationships between youth and their families or caregivers it was found that poor relationships were strongly related to depression symptoms (Miller et al., 2016; Spence et al., 2016).

"I am called Jl, and it helped me now I can talk to people, I was hopeless but now... yes, I am of importance. When I saw that I am this way, I felt that there is no life and that I am not important." (JI, age21, Kangemi)

One of the adolescent mothers narrated how HIV-related stigma used to torment her before the before our intervention:

"I know myself since I know how I used to feel; when I sit down, I ask myself, 'what kind of life is this?' I used to feel guilty. I don't want people's stories. I just feel that a story may arise and reach the point of the infection, so what will I say? You know at that point you will just be forced to remain silent; you will not talk-you will never have what to say because they are negative, and you are positive, and they want to talk about that infection --." (JA, age22, Kariobangi)

It was clear that irritability was negatively affecting communication with their partners as one of the participants narrated how she used to live while having depressive symptoms:

"In the past, whenever I could get angry, I could not cook... I cannot eat, if it is talking to people, I cannot talk to him; everybody sits apart when it comes to washing, everybody washes their clothes." (SK, age23, Kangemi)

Besides, adolescent participants could appreciate that IPT-G helped them alleviate depressive symptoms (social isolation, anger, hopelessness, and low mood). Most of them reported better sleep patterns, good appetite, increased social interactions, and decreased HIV-related stigma. Our study population was noted to have several challenges which seemed to support previous studies where they found out that adolescents living with HIV are more vulnerable to mental health disorders due to medical and psychosocial stressors associated with HIV/AIDS (Mellins \& Malee, 2013; Nanni et al., 2015). There is no 
doubt that our intervention addressing depression will improve adherence to ART among our study participants, which is key to good quality of life (Sin \& DiMatteo, 2014).

"It has helped me when I am with people I have accepted myself the way I am and then anger issues nowadays are not there, at least I can make friends; in the past, I could not make friends, but now at least I can sit with somebody and share something with her that is helpful." (SA, age23, Kariobangi)

Isolation was one of the maladaptive behaviors associated with depressive symptoms as indicated by on of the adolescent mother:

"I used to lock myself in the house, but currently, I can get out and make stories with neighbors, when I am called for a job / can go." (RA, age 18, Kangemi)

The male partner's role towards how relationships evolve through pregnancy and motherhood among adolescents is worth looking into to help adolescent girls in abusive marriages. One qualitative study suggested that postpartum adolescents living with their partners or caregivers will benefit from social support as postpartum adolescents transit early motherhood challenges (UNESCO, 2017). See vignette from our participants here highlighting this point further:

"I am FW; it has helped me I am not the same as I used to be; I used to be angry; I could get out of the house at night due to anger. Now we talk well in the house... yes [Laughter]." (FW, age21, Kariobangi)

We noted the devastating effects of depression as highlighted by one of the participants on how isolation, marital conflict, and persistent distress used to affect her daily living:

"I think I was depressed; I used to sit in the house and had no friends. But when I started coming to this group, I found friends here, outside I have also made friends. I used to be stressed as to why my husband doesn't go to work and frequent disagreements. But since I started coming here for advice, I realized that I am not the only one who has problems, so for me, it has gotten out; I just feel that it has helped me a lot, stress is usual, but for now, I feel stress free." (FW, age21, Kariobangi)

Our study acknowledges that adolescents living with HIV are vulnerable to negative community perceptions, which agrees with a similar study in Uganda (Ashaba et al., 2019). These could manifest with suicidal ideations.

"At the first time, I wanted to kill myself [Inaudible], I have children and they could become orphans. The moment I came in this group, it has helped me until now my children are grown, and I have even started working harder because the other one is in grade two, the other is still little, but you advised me." (PN, age24, Kariobangi)

Spouses supporting postpartum adolescents with financial and social provision to return to school are likely to minimize future unplanned or unwanted pregnancies and enable them to acquire better lives and even for their children (Human Rights Watch, 2018). One of the participants acknowledged therapy 
sessions improved her interpersonal relationship with her male partner and could enjoy functional changes in her life.

"We have agreed with my husband that I am going back to school - -In the past, I used to wonder how he views me." (Jl, age21, Kangemi)

HIV affects adolescents and the unpleasant outcomes are indirectly transferred to the child (González et al., 2017) as shown by one, the participants who feel could have died of a stressful life, but the sessions helped her.

"I give back thanks for he has brought us from far because right now I could be in the ground [Laughter], so may God give him (YO) strength for him to continue with that spirit." (PN, age24, Kariobangi)

Early sexual intimacy with the opposite gender predisposes girls to unplanned and unwanted pregnancy with possibilities of dropping out of school and even lack skills to gain employment (Erken, ArthurErken, A., \& Schensul \& Schensul, 2019). Research has shown that early unintended pregnancy is a risk factor for later HIV infections among adolescents (Christofides et al., 2014). HIV-related stigma remains to be addressed fully in SSA. Systematic reviews have associated it with delays in treatment and difficulties in adhering to ART (Ammon et al., 2018; Croome et al., 2017). As an illustration to share this point further, one of our participants was grateful for participating in the sessions and shared her positivity:

"I can remember there is one who said after the sessions, 'nowadays I can get out and talk with women, I can go out of the gate because when I was alone, I felt that I am not okay because I have HIV and I have given birth at a younger age. But now I have gotten that courage after these sessions to go outside I can talk, I have that courage,' so that made her feel that they are many and she is not alone." (LN, age 34, CHA, Kangemi)

One of the CHV encountered sudden death outside the study area, which caused a lot of grief among the participants. Besides, we realized most of our CHWs had experienced the loss of a loved one and were also struggling with healing, which our sessions also supported them as they narrated to us. The $\mathrm{CHWs}$ were affected by the loss of a colleague (CA), and in addition to other previous bereavement worsened their state (Shear, 2012), and IPT-G helped them cope:

"CA also left me, he was my friend, and it drew me so much down, but now I am fine, isn't it? - - During CA's time of demise, it was like everybody in Kangemi felt like was carrying something [Silence]." (LN, age 34, CHA, Kangemi)

One of the CHW expressed how IPT-G helped her process the thoughts and emotions of loss and grief associated with past incidents:

"It has helped me a lot, the second thing let me say I was given a husband by Kangemi people, when we were doing training, and I lost the husband (refers to CA, deceased CHV), so IPT helped me to go through the loss and grief, anyway it was not a real husband [Laughter]. But he was a very good friend of mine. 
Anyway, when I was undergoing through the sessions, I lost most of very important people, but IPT helped me. You know when we were talking to these girls, and they are also expressing, "I lost my kid, I lost my daddy, and I was also like it was like me losing the people whom I care about, so we were going through these together. It was a process for all of us, so it healed me, and it healed them; that was very good." (EO, age 24, CHV, Kariobangi)

The community health assistant was mourning the loss of her child during the sessions and had to say this in appreciation of the intervention:

"- - and when I came here, I was so much stressed, and it could have resulted in depression because there is something, I lost my child on delivery, then I lost both parents at the same time. So, when we started talking, I felt that I had put the load down, you get it? so when we continued and reached the middle, and I realized that I am good." (NG, age 43, CHV, Kangemi)

Continuous supportive supervision was appreciated by the $\mathrm{CHWs}$ and they felt that all their concerns arising from the weekly session was addressed promptly and adequately. During our group sessions, supportive supervision emphasized joint problem solving, mentoring, and two-way communication between the researchers and the CHWs (Lehmann \& Sanders, 2007; Lewin et al., 2005).

"It was just like Kangemi; at first for the people with whom you are not familiar enough, they could not open up; you ask her a question, and she feels like where do you want to lock and take her? But now the second time they will be free, and the third time she will feel like "I can remember what happened to me and how it is on somebody else,' because we had supervision like from CHA and MK and could correct us when wrong and it becomes normal." (SN, age 65, Kariobangi)

Furthermore, it was very encouraging to hear from the $\mathrm{CHWs}$ that our participants after intervention became role models in the community by imparting skills of managing their day-to-day life issues. For CHWs and adolescents to be able to understand the concept of IPT-G and even use it to help others, the learning cycle was achieved by both actual experiences and empowering them to practice through supportive supervision (Huber, 1991; Newell, 2005)

"I think even these girls have become role models in the community... we told them 'if you find somebody who is in a situation maybe you can assist and feel that it closer to yours or it is similar to yours, you are now empowered, and you can help this person at your level and if you feel that it is difficult is when you can refer.' Still, now they are doing on their own, which is good." (EO, age 24, CHV, Kariobangi)

One of the CHA affirmed that time for IPT-G sessions was easily embedded into their routine activities since it consumes 90 minutes only once a week.

"Not a burden because it was usually once a week, and if you are meeting those clients later, it is the one in which you can negotiate the time that you will meet, so I don't think, maybe if others think otherwise." (LN, age 34, CHA, Kangemi) 
Nevertheless, several CHWs acknowledged the lack of designated space for mental health services as one of the limitations towards adopting IPT-G delivery to routine PMTCT services:

"I think for us (in) Kariobangi we had a big challenge when it came to the venue of the meeting because sometimes you find we are here sometimes we are displaced at the tent, maybe the other tent is very dirty, sometimes we are in this other tent we come here displaced, so it was a very big challenge [Cross talk] - -." (EO, age 24, Kariobangi)

The space to administer mental health services was missing within the health centers as shown by how we had to improvise a room for the sessions:

"We were okay; we had been given the maternity, a place somewhere... You see, if we close the middle of the room too and pull the curtains, it was so good; it didn't have an issue." (LN, age 34, Kangemi)

Another $\mathrm{CHW}$ seemed helpless of the situation and consented to the state of the available space despite all the challenges associated with it:

"But let's just say it was okay; even if it is bad, it is our place, so we cannot say that it is bad [Laughter], but it was fine." (JA, age 24, Kangemi)

The lack of specified venue for mental health services posed uncertainty on effective service delivery for the CHWs:

"The space was okay; it was somewhere where we don't have issues with noise, but we don't know next." (SN, age 65, Karionbangi)

We were able to form a strong collaborative team by creating a WhatsApp group and took issues of the CHWs and PPA with a lot of importance by demonstrating practical empathy, thus improving commitment for all of us in the study process. The use of technology proved equally useful, just like a Nigerian study on psychological intervention for adolescents living with HIV where support groups were engaged using Facebook groups for a 5-weekly session. The ability for them to interact, learn more about HIV, share experiences, and their fears affirmed that social media could help them cope with their status (Dulli et al., 2018).

"When I lost my child on delivery, I also want to thank YO, I don't know what to tell him, but there is a time I looked and realized that he is a very different person. We hadn't known each other- we had known each other for only three days, but when I had a problem he came with MK to my house and consoled me, and I felt that it wasn't even about friendship, they are just part of like my family, and he helped me." (LN,age 34,CHA, Kangemi)

One of the CHW underscored the potential impact IPT-G could have in the community as indicated in her explanation: 
"- - it has changed us, as much as we were the teachers, but we feel that it helped us. So I just pray that more of that kind comes and the way I said that when you just change one person he/she will change five others and those five others will change others and at the end of the day you may find that you have changed the whole country and even the world, so thank you". (JA,age 24,Kangemi)

Generally, our findings of challenges affecting PPA did not come as a surprise considering previous studies had also identified that perinatal adolescents, who are also parenting, face several difficulties, such as social stigma, lack of emotional support, poor healthcare access, and stresses around new life adjustments (Kumar et al., 2018). Our IPT-G intervention helped adolescents by improving their interpersonal relationships, communication processes, and overall mental health.

\section{Strengths}

We were able to qualitatively establish acceptability and feasibility of IPT-G delivered to postpartum adolescents living with HIV by CHWs in primary health care settings. The two study sites make the findings more reliable for a representative outcome for low-resource urban settings.

\section{Limitations}

Despite all the exciting, positive impact on the participants' lives from this intervention, as seen from the qualitative findings, the sample size was not powered. Thus, other quantitative results may not offer strong enough argument when discussing the intervention's impact on this vulnerable population.

\section{Conclusion}

The shortage of trained mental health workers has led to inaccessibility of mental health services both in urban and rural settings. To enhance mental health services to the broader population, our study sought to assess acceptability and feasibility of IPT-G being delivered to postpartum adolescents living with HIV by $\mathrm{CHWs}$ in Nairobi area at primary health care within routine clinical settings. Our findings affirm that this intervention has a promise of being delivered by $\mathrm{CHWs}$ for this specific population and the need for supportive supervision to enhance fidelity. We recommend a follow-up study with a larger representative sample size from diverse community within urban and rural settings with a view to scaling-up IPT-G at the primary health care level in all counties.

\section{Abbreviations}

CHA: Community Health Assistant

$\mathrm{CHV}$ : Community Health Volunteer

EPDS: Edinburgh Postnatal Depression Scale

IPT-G: Group Interpersonal Psychotherapy 
HIV: Human Immunodeficiency Syndrome

LMICs: Low-and -Middle-Income countries

PMTCT: Prevention of Mother-to-Child Transmission

PPA: Postpartum adolescents

PPD: Postpartum depression

\section{Declarations}

The authors declare that they have no competing interests.

\section{Acknowledgements}

I acknowledged the efforts demonstrated by $\mathrm{CHVs}$ who participated in this study, health center-in -Charge, Prof. Ruth Nduati of Department of MMed (Padiatrics), University of Nairobi-Chair of the Advisory group and technical advisor in this study, Dr. Alfred Osoti, Lecturer, Department of Obstetrics and Gynaecology, University of Nairobi, Dr. Beatrice Amugune, Senior Lecturer Department of Pharmacy, University of Nairobi, Martha Kagoya, MSc Clinical Psychologist, Department of Psychiatry, University of Nairobi who was Clinical supervisor to his study and Vincent Nyongesa, the research assistant. I also acknowledge Sahiba Turgesen for proof-reading and editing of this manuscript.

\section{Authors Contributions}

$\mathrm{YO}$ is the lead researcher towards his Ph.D. dissertation and has led the writing of the manuscript, MK, KL, and JG are the author's supervisors. All supervisors guided in the development of IPT-G protocol and interpretation of results. All authors participated in manuscript editing and approved the final manuscript for publication.

\section{Ethical Approval}

The study was reviewed and approved by The Kenyatta National Hospital-University of Nairobi Ethics and Research Committee (Approval No. P97/02/2018). All participants of the study signed informed consent.

\section{References}

1. Ammon, N., Mason, S., \& Corkery, J. M. (2018). Factors impacting antiretroviral therapy adherence among human immunodeficiency virus-positive adolescents in Sub-Saharan Africa: a systematic review. In Public Health (Vol. 157, pp. 20-31). Elsevier B.V.

https://doi.org/10.1016/j.puhe.2017.12.010

2. Angwenyi, V., Kamuya, D., Mwachiro, D., Marsh, V., Njuguna, P., \& Molyneux, S. (2013). Working with Community Health Workers as "Volunteers" in a Vaccine Trial: Practical and Ethical Experiences and 
Implications. Developing World Bioethics, 13(1), 38-47. https://doi.org/10.1111/dewb.12015

3. Ashaba, S., Cooper-Vince, C. E., Vořechovská, D., Rukundo, G. Z., Maling, S., Akena, D., \& Tsai, A. C. (2019). Community beliefs, HIV stigma, and depression among adolescents living with HIV in rural Uganda. African Journal of AIDS Research, 18(3), 169-180.

https://doi.org/10.2989/16085906.2019.1637912

4. Bhana, A., Mellins, C. A., Small, L., Nestadt, D. F., Leu, C. S., Petersen, I., Machanyangwa, S., \& McKay, M. (2016). Resilience in perinatal HIV+ adolescents in South Africa. AIDS Care - Psychological and Socio-Medical Aspects of AIDS/HIV, 28, 49-59. https://doi.org/10.1080/09540121.2016.1176676

5. Christofides, N. J., Jewkes, R. K., Dunkle, K. L., Nduna, M., Shai, N. J., \& Sterk, C. (2014). Early adolescent pregnancy increases risk of incident HIV infection in the eastern cape, south africa: A longitudinal study. Journal of the International AIDS Society, 17. https://doi.org/10.7448/IAS.17.1.18585

6. Cox, J. L., Holden, J. M., \& Sagovsky, R. (1987). Detection of Postnatal Depression. British Journal of Psychiatry, 150(6), 782-786. https://doi.org/10.1192/bjp.150.6.782

7. Croome, N., Ahluwalia, M., Hughes, L. D., \& Abas, M. (2017). Patient-reported barriers and facilitators to antiretroviral adherence in sub-Saharan Africa. In AIDS (Vol. 31, Issue 7, pp. 995-1007). Lippincott Williams and Wilkins. https://doi.org/10.1097/QAD.0000000000001416

8. Cruess, D. G., Evans, D. L., Repetto, M. J., Gettes, D., Douglas, S. D., \& Petitto, J. M. (2003). Prevalence, diagnosis, and pharmacological treatment of mood disorders in HIV disease. Biological Psychiatry, 54(3), 307-316. https://doi.org/10.1016/s0006-3223(03)00318-4

9. Dawson, A. J., Buchan, J., Duffield, C., Homer, C. S. E., \& Wijewardena, K. (2014). Task shifting and sharing in maternal and reproductive health in low-income countries: a narrative synthesis of current evidence. Health Policy and Planning, 29(3), 396-408. https://doi.org/10.1093/heapol/czt026

10. de Oliveira, T., Kharsany, A. B. M., Gräf, T., Cawood, C., Khanyile, D., Grobler, A., Puren, A., Madurai, S., Baxter, C., Karim, Q. A., \& Karim, S. S. A. (2017). Transmission networks and risk of HIV infection in KwaZulu-Natal, South Africa: a community-wide phylogenetic study. The Lancet HIV, 4(1), e41-e50. https://doi.org/10.1016/S2352-3018(16)30186-2

11. Dinwiddie, K. J., Schillerstrom, T. L., \& Schillerstrom, J. E. (2018). Postpartum depression in adolescent mothers. Journal of Psychosomatic Obstetrics \& Gynecology, 39(3), 168-175. https://doi.org/10.1080/0167482X.2017.1334051

12. Dulli, L., Ridgeway, K., Packer, C., Plourde, K. F., Mumuni, T., Idaboh, T., Olumide, A., Ojengbede, O., \& McCarraher, D. R. (2018). An Online Support Group Intervention for Adolescents Living with HIV in Nigeria: A Pre-Post Test Study. JMIR Public Health and Surveillance, 4(4), e12397. https://doi.org/10.2196/12397

13. Erken, ArthurErken, A., \& Schensul, B. D. (2019). U. S. of the W. P. https://www. unfpa. org/sites/default/files/pub-pdf/UNFPA_PUB_2019_EN_State_of_World_Population. pd., \& Schensul, B. D. (2019). UNFPA State of the World Population. UNFPA_PUB_2019_EN_State_of_World_Population.pdf 
14. González, R., Rupérez, M., Sevene, E., Vala, A., Maculuve, S., Bulo, H., Nhacolo, A., Mayor, A., Aponte, J. J., Macete, E., \& Menendez, C. (2017). Effects of HIV infection on maternal and neonatal health in southern Mozambique: A prospective cohort study after a decade of antiretroviral drugs roll out. PLOS ONE, 12(6). https://doi.org/10.1371/journal.pone.0178134

15. Huber, G. P. (1991). Organizational Learning: The Contributing Processes and the Literatures. Organization Science, 2(1), 88-115. https://doi.org/10.1287/orsc.2.1.88

16. Human Rights Watch. (2018). Africa: Pregnant Girls, Young Mothers Barred from School / Human Rights Watch. https://www.hrw.org/news/2018/06/14/africa-pregnant-girls-young-mothers-barredschool

17. Januraga, P. P., Mooney-Somers, J., \& Ward, P. R. (2014). Newcomers in a hazardous environment: a qualitative inquiry into sex worker vulnerability to HIV in Bali, Indonesia. BMC Public Health, 14(1), 832. https://doi.org/10.1186/1471-2458-14-832

18. Kamau, J. W., Kuria, W., Mathai, M., Atwoli, L., \& Kangethe, R. (2012). Psychiatric morbidity among HIV-infected children and adolescents in a resource-poor Kenyan urban community. AIDS Care, 24(7), 836-842. https://doi.org/10.1080/09540121.2011.644234

19. Kim, M. H., Mazenga, A. C., Devandra, A., Ahmed, S., Kazembe, P. N., Yu, X., Nguyen, C., \& Sharp, C. (2014). Prevalence of depression and validation of the Beck Depression Inventory-II and the Children's Depression Inventory-Short amongst HIV-positive adolescents in Malawi. Journal of the International AIDS Society, 17, 18965. https://doi.org/10.7448/IAS.17.1.18965

20. Kredo, T., Adeniyi, F. B., Bateganya, M., \& Pienaar, E. D. (2014). Task shifting from doctors to nondoctors for initiation and maintenance of antiretroviral therapy. In Cochrane Database of Systematic Reviews (Vol. 2014, Issue 7). John Wiley and Sons Ltd.

https://doi.org/10.1002/14651858.CD007331.pub3

21. Kumar, M., Huang, K.-Y., Othieno, C., Wamalwa, D., Madeghe, B., Osok, J., Kahonge, S. N., Nato, J., \& McKay, M. M. (2018). Adolescent Pregnancy and Challenges in Kenyan Context: Perspectives from Multiple Community Stakeholders. Global Social Welfare, 5(1), 11-27.

https://doi.org/10.1007/s40609-017-0102-8

22. Lehmann, U., \& Sanders, D. (2007). Community Health Workers: What do we Know About Them? The State of Evidence on Programmes, Activities, Costs and Impact on Health Outcomes of Using Community Health Workers. January.

23. Lewin, S., Dick, J., Pond, P., Zwarenstein, M., Aja, G. N., van Wyk, B. E., Bosch-Capblanch, X., \& Patrick, M. (2005). Lay health workers in primary and community health care. In Cochrane Database of Systematic Reviews. John Wiley \& Sons, Ltd. https://doi.org/10.1002/14651858.cd004015.pub2

24. Martinez, J., Chakraborty, R., Aldrovandi, G. M., Chadwick, E. G., Cooper, E. R., Kourtis, A., Collins, E. M., Dominguez, K. L., Mofenson, L. M., Schutze, G. E., \& Emanuel, A. (2014). Psychosocial support for youth living with HIV. Pediatrics, 133(3), 558-562. https://doi.org/10.1542/peds.2013-4061

25. McCain, G. C. (1988). Content analysis: a method for studying clinical nursing problems. Applied Nursing Research: ANR, 1(3), 146-147. https://doi.org/10.1016/s0897-1897(88)80029-6 
26. Mellins, C. A., \& Malee, K. M. (2013). Understanding the mental health of youth living with perinatal HIV infection: lessons learned and current challenges. Journal of the International AIDS Society, 16, 18593. https://doi.org/10.7448/IAS.16.1.18593

27. Miller, L., Hlastala, S. A., Mufson, L., Leibenluft, E., \& Riddle, M. (2016). Interpersonal Psychotherapy for Adolescents With Mood and Behavior Dysregulation: Evidence-Based Case Study. EvidenceBased Practice in Child and Adolescent Mental Health, 1(4), 159-175. https://doi.org/10.1080/23794925.2016.1247679

28. Ministry of Health. (2020). Kenya Community Health Policy 2020 - 2030.

29. Mufson, L., Gallagher, T., Dorta, K. P., \& Young, J. F. (2004). A group adaptation of interpersonal psychotherapy for depressed adolescents. American Journal of Psychotherapy, 58(2), 220-237.

30. Mundeva, H., Snyder, J., Ngilangwa, D. P., \& Kaida, A. (2018). Ethics of task shifting in the health workforce: Exploring the role of community health workers in HIV service delivery in low- and middleincome countries. BMC Medical Ethics, 19(1), 1-11. https://doi.org/10.1186/s12910-018-0312-3

31. Murray, K. R., Dulli, L. S., Ridgeway, K., Dal Santo, L., De Mora, D. D., Olsen, P., Silverstein, H., \& McCarraher, D. R. (2017). Improving retention in HIV care among adolescents and adults in low- and middle-income countries: A systematic review of the literature. PLOS ONE, 12(9). https://doi.org/10.1371/journal.pone.0184879

32. Mwai, G. W., Mburu, G., Torpey, K., Frost, P., Ford, N., \& Seeley, J. (2013). Role and outcomes of community health workers in HIV care in sub-Saharan Africa: A systematic review. In Journal of the International AIDS Society (Vol. 16). https://doi.org/10.7448/IAS.16.1.18586

33. NACC. (2016). Www.Nacc.or.Ke. Progress, Response.

34. Nanni, M. G., Caruso, R., Mitchell, A. J., Meggiolaro, E., \& Grassi, L. (2015). Depression in HIV infected patients: a review. Current Psychiatry Reports, 17(1), 530. https://doi.org/10.1007/s11920-014-05304

35. NASCOP - Kenya, 2015. (2016). Kenya AIDS estimates, 2015. www.nascop.or.ke\%0Awww.nascop.or.ke

36. Newell, S. (2005). Knowledge Transfer and Learning: Problems of Knowledge Transfer Associated With Trying To Short-Circuit the Learning Cycle. JISTEM Journal of Information Systems and Technology Management, 2(3), 275-290. https://doi.org/10.4301/s1807-17752005000300003

37. Nunes, A. P., \& Phipps, M. G. (2013). Postpartum Depression in Adolescent and Adult Mothers: Comparing Prenatal Risk Factors and Predictive Models. Maternal and Child Health Journal, 17(6), 1071-1079. https://doi.org/10.1007/s10995-012-1089-5

38. Okawa, S., Mwanza Kabaghe, S., Mwiya, M., Kikuchi, K., Jimba, M., Kankasa, C., \& Ishikawa, N. (2018). Psychological well-being and adherence to antiretroviral therapy among adolescents living with HIV in Zambia. AIDS Care - Psychological and Socio-Medical Aspects of AIDS/HIV, 30(5), 634642. https://doi.org/10.1080/09540121.2018.1425364

39. Sangsawang, B., Wacharasin, C., \& Sangsawang, N. (2019). Interventions for the prevention of postpartum depression in adolescent mothers: a systematic review. Archives of Women's Mental 
Health, 22(2), 215-228. https://doi.org/10.1007/s00737-018-0901-7

40. Schunter, B. T., Cheng, W.-S., Kendall, M., \& Marais, H. (2014). Lessons Learned From a Review of Interventions for Adolescent and Young Key Populations in Asia Pacific and Opportunities for Programming. JAIDS Journal of Acquired Immune Deficiency Syndromes, 66, S186-S192. https://doi.org/10.1097/QAl.0000000000000185

41. Sekhon, M., Cartwright, M., \& Francis, J. J. (2017). Acceptability of healthcare interventions: An overview of reviews and development of a theoretical framework. BMC Health Services Research, 17(1), 1-13. https://doi.org/10.1186/s12913-017-2031-8

42. Shear, M. K. (2012). Grief and mourning gone awry: Pathway and course of complicated grief. Dialogues in Clinical Neuroscience, 14(2), 119-128.

43. Sherr, L., Clucas, C., Harding, R., Sibley, E., \& Catalan, J. (2011). HIV and Depression - a systematic review of interventions. Psychology, Health \& Medicine, 16(5), 493-527. https://doi.org/10.1080/13548506.2011.579990

44. Sin, N. L., \& DiMatteo, M. R. (2014). Depression Treatment Enhances Adherence to Antiretroviral Therapy: a Meta-Analysis. Annals of Behavioral Medicine, 47(3), 259-269. https://doi.org/10.1007/s12160-013-9559-6

45. Spence, S. H., O’Shea, G., \& Donovan, C. L. (2016). Improvements in Interpersonal Functioning Following Interpersonal Psychotherapy (IPT) with Adolescents and their Association with Change in Depression. Behavioural and Cognitive Psychotherapy, 44(3), 257-272. https://doi.org/10.1017/S1352465815000442

46. Torres, R., Goyal, D., Burke-Aaronson, A. C., Gay, C. L., \& Lee, K. A. (2017). Patterns of Symptoms of Perinatal Depression and Stress in Late Adolescent and Young Adult Mothers. Journal of Obstetric, Gynecologic \& Neonatal Nursing, 46(6), 814-823. https://doi.org/10.1016/j.jogn.2017.08.002

47. UNAIDS. (2018). Global AIDS Update 2018 Miles To Go: Closing Gaps Breaking Barriers Righting Injustices. Unaids, http://www.unaids.org/sites/default/files/media_as. https://doi.org/10.1111/j.1600-6143.2011.03542.x

48. UNAIDS. (2019). In sub-Saharan Africa, three in five new HIV infections among 15-19-year-olds are among girls. 2019.

https://www.unaids.org/sites/default/files/women_girls_hiv_sub_saharan_africa_en.pdf

49. UNAIDS and Stop AIDS Alliance. (2015). Communities deliver. 23-80.

50. UNESCO. (2017). UNESCO. Early and Unintended Pregnancy \& the Education Sector (ED/IPS/HAE/2517/01REV). Paris; 2017. http://unesdoc.unesco.org/images/0025/002515/251509E.pdf. - Google Search.

51. Wagner, G. J., Ghosh, B., Barbara, D., \& Sebastian, M. (2020). Changes in ART Adherence Relate to Changes in depression as Well ! Evidence for the Bi - directional Longitudinal Relationship Between Depression and ART Adherence from a Prospective Study of HIV Clients in Uganda. AIDS and Behavior, 24(6), 1816-1824. https://doi.org/10.1007/s10461-019-02754-8 
52. WHO-Unicef. (1978). ALMA-ATA Primary Health Care. International Conference on Primary Health Care, 63.

53. WHO. (2006). Treat, train, retain: the AIDS and health workforce plan: report on the Consultation on AIDS and Human Resources for Health, WHO, Geneva, 11-12 May, 2006. IAPAC Monthly, 12(5), 144146. http://www.ncbi.nlm.nih.gov/pubmed/17249139

54. WHO. (2007). World Health organisation: Task Shifting Global recommendations and guidelines Geneva Switzerland.

55. WHO. (2017). WHO I WHO called to return to the Declaration of Alma-Ata. WHO.

56. WHO, \& Columbia, U. (2016). Group Interpersonal Therapy (Ipt) for Depression. World Health Organization, 100. https://doi.org/10.1176/appi.ajp.2016.16121392

\section{Tables}


Table 1

Sociodemographic characteristics of the respondents

\begin{tabular}{|c|c|c|c|c|}
\hline Variable & Category & $\begin{array}{l}\text { Overall }(\mathrm{N}= \\
24)\end{array}$ & $\begin{array}{l}\text { Intervention (N } \\
=12)\end{array}$ & $\begin{array}{l}\text { Waitlist }(n= \\
\text { 12) }\end{array}$ \\
\hline \multirow[t]{2}{*}{ Age } & $18-20$ Years & $3(12.5 \%)$ & $2(66.7 \%)$ & $1(33.3 \%)$ \\
\hline & 21-24 Years & $21(87.5 \%)$ & $10(47.6 \%)$ & $11(52.4 \%)$ \\
\hline \multirow[t]{2}{*}{ Marital Status } & Without a partner & $7(29.2 \%)$ & $4(57.1 \%)$ & $3(42.9 \%)$ \\
\hline & With a Partner & $17(70.8 \%)$ & $8(47.1 \%)$ & $9(52.9 \%)$ \\
\hline \multirow[t]{2}{*}{ Education Level } & $\begin{array}{l}\text { Primary and } \\
\text { Below }\end{array}$ & $11(45.8 \%)$ & $4(36.4 \%)$ & $7(63.6 \%)$ \\
\hline & $\begin{array}{l}\text { Secondary and } \\
\text { above }\end{array}$ & $13(54.2 \%)$ & $8(61.5 \%)$ & $5(38.5 \%)$ \\
\hline \multirow[t]{2}{*}{ Occupation } & Employed & $5(20.8 \%)$ & $4(80.0 \%)$ & $1(20.0 \%)$ \\
\hline & Unemployed & $19(79.2 \%)$ & $8(42.1 \%)$ & $11(57.9 \%)$ \\
\hline \multirow{2}{*}{$\begin{array}{l}\text { Income per month (Kenya } \\
\text { shillings) }\end{array}$} & $0-10000$ & $22(91.7 \%)$ & $11(50.0 \%)$ & $11(50.0 \%)$ \\
\hline & $10001-20000$ & $2(8.3 \%)$ & $1(50.0 \%)$ & $1(50.0 \%)$ \\
\hline \multirow[t]{4}{*}{ Number of children } & 1 & $11(45.8 \%)$ & $5(45.5 \%)$ & $6(54.5 \%)$ \\
\hline & 2 & $8(33.3 \%)$ & $5(62.5 \%)$ & $3(37.5 \%)$ \\
\hline & 3 & $3(12.5 \%)$ & $1(33.3 \%)$ & $2(66.7 \%)$ \\
\hline & 4 & $2(8.3 \%)$ & $1(50.0 \%)$ & $1(50.0 \%)$ \\
\hline \multirow[t]{2}{*}{ Reaction to HIV status } & Accepted & $13(54.2 \%)$ & $9(69.2 \%)$ & $4(30.8 \%)$ \\
\hline & Not Accepted & $11(45.8 \%)$ & $3(27.3 \%)$ & $8(72.7 \%)$ \\
\hline \multirow[t]{2}{*}{ HIV status of child } & Negative & $10(41.7 \%)$ & $5(50.0 \%)$ & $5(50.0 \%)$ \\
\hline & Not Sure & $14(58.3 \%)$ & $7(50.0 \%)$ & $7(50.0 \%)$ \\
\hline \multirow[t]{2}{*}{ Intimate partner Violence } & Yes & $13(54.2 \%)$ & $6(46.2 \%)$ & $7(53.8 \%)$ \\
\hline & No & $11(45.8 \%)$ & $6(54.5 \%)$ & $5(45.5 \%)$ \\
\hline
\end{tabular}


Table 2

Data collection instruments

\section{Constructs/ Activities and domains}

Depression EPDS scores for postpartum adolescents

Weekly

rating

screening to

assess change

in scores

IPT Assess quality of Interpersonal relationship for postpartum

inventory adolescents

Weekly

questionnaire to

assess

interaction

changes

Knowledge Make field notes during session which records:

CHWs weekly

of IPT and

i) Depression score for each participant

delivery

skills

ii) Progress in IPT problem areas

notes during

session (Filled

by the $\mathrm{CHW}$ ).

iii)Plan for next session

If the participant fails to attend session or dropped out, the

$\mathrm{CHWs}$ should state the reason and plans for contacting her

IPT process

and fidelity
Clinical supervisor issues printed copies ton protocol to $\mathrm{CHWs}$ to guide them on tasks, steps and techniques to be used from pregroup phase, initial phase (session 1), middle phase (session 27) and termination phase (session 8)
Session-bysession IPT activities (Issued by clinical supervisor to CHWs).

IPT Knowledge test (Clinical supervisor evaluates $\mathrm{CHWs}$ during sessions).

iii) 0 Point is answer is incorrect. The $\mathrm{CHWs}$ should be able to answer $70 \%$ of the questions correctly by scoring 21 points

Competency: CHW's level of IPT-G understanding from the training, piloting, supervision and mentorship. Clinical supervisor reports the strengths, difficulties and prescribe plans for improvement.
Pre-group phase (Clinical supervisor asses individual $\mathrm{CHW}$ on their ability to administer IPT-

G)

FGDs, Key Informants interviews, and observations.
Feasibility and acceptability
Clinical supervisor and research assistant conducted FGDs for CHWs prior and after IPT-G intervention. FGDs was also conducted for PPAs after intervention at the 4 months of followup. In-depth interviews for: Nursing officer in-charge, Laboratory technologist, PMTCT-Nurse, CHA, and Mentor-mother at the two study sites. 
Table 3

Ideas that appealed to the adolescents

\section{IPT-G informed Relevant Quotations hemes}

Improved communication

mproved anger management
"I can say that we learnt how to communicate, communication." (MM, age24, Kangemi)

"I had an issue with my parents, but now we are okay, and we communicate well". (RJ, age23, Kangemi)

"About my estranged partner, I can say that at the moment, even though we have not yet met, we are fine because we are communicating." (MM, age24, Kangemi)

"This group has helped me in terms of communication." (JF, age24, Kangemi)

"It helped me to interact with people." (RA, age21, Kangemi)

"I am called S, but that one is informal, but in reality, I am called NC; by the way, even me, it has helped me so much, I have seen that several things have changed. The anger I used to have is no longer there; I just feel that I am okay." (NC, age24, Kariobangi)

"For me, I got assistance because even now I see that getting angered is not so much there, I just see that life is okay; I don't want- I mean I know how to control anger, and it cannot rise the way it used to happen to me." (JA, age22, Kariobangi)

IPT-G delivery process
"They were nice on my side, caring, they used to concentrate on us, they were social; let me say they were just nice." (JF, age24, Kangemi)

"They used to understand us." (Jl, age21, Kangemi)

"They were nice people; in case you got stuck on something they could help you [Inaudible]." (SK, age23, Kangemi)

"They used simple terms.... and for those that were difficult they used to elaborate." (MR, age24, Kangemi)

"They were just using simple terms." (RA, age18, Kangemi) 


\section{IPT-G informed Relevant Quotations hemes}

Overall

Perceptions towards IPT by postpartum adolescents
"I can tell him(lead researcher) thanks because he has helped us so much, we had stress, we were lonely but the way he organized this group it has helped us and we have found means of helping our colleagues out there and that he should just continue that way without giving up and God grant him strength and life." (FW, age21, Kariobangi)

"I can tell him (lead researcher) that he assisted us so much because if some of us could still be where we used to be then, we wouldn't exist till now; but he did an important thing and assisted us so he should continue that way and may God bless him." (NC, age24, Kariobangi)

"I can tell him (lead researcher) thanks for creating this organization it has helped all of us on how we can also educate other people to be happy, and he should just continue with that spirit." (LA, age19, Kariobangi)

"I can tell him thanks so much, he helped us a great deal because we came here with stress, but we have been assisted, and we say thank you so much and it should just continue this way [Crosstalk]." (SA, age23, Kariobangi)

"I want to tell him (lead researcher) thanks for he has made me able to believe in myself, and may God give him strength to proceed with this program for others who are behind and are like us to get assistance." (EA, age24, Kariobangi)

"For me, it had helped me, I have lived positively and I am not bothered by what people say [Some silence]." (LA, age19, Kariobangi)

"I am EAO and for me this content made me more aggressive, I mean I am not the way I used to be; I have many differences such that when I walk in other places I am not afraid I know who I am now, I have decided to live a positive life and I am used to it, and if I see someone else I teach her the way I have been taught." (EO, age24, Kariobangi) 
Table 4

Postpartum adolescents' understanding of IPT-G intervention

\section{IPT theme Quotations}

Overall impact of IPT (Reduce social isolation, anger, hopelessness, low mood)
"I used to stay in the house asking myself 'who am I for sure? Whose friend can I be?' 'so, I feel like even taking poison, I think of many things; but I have seen a great difference; when he comes and we disagree it means verbal exchange of all kinds [Laugh] I talk and talk he gets angry and leave only to return very late at night - -." (NC, age24, Kariobangi)

"It was worse until hey! I used to keep quiet so much because I used to feel whenever somebody talks to me just a little then I get angry and I just wish that we fight [Laughter] I mean I used to get extremely angry --." (JA, age22, Kariobangi)

"I was depressed but I had several regrets as I was just questioning myself but nowadays it is over. The regrets were 'why have I become pregnant early?" (LA, age19, Kariobangi)

"I am another one; whenever someone could anger me just a little I could moody, sitting in the bed with tears, and when I cook the food cannot even be eaten because of too much salt [Laughter] or raw ugali; but for now I have changed and I am good, even if you talk l act like l am not hearing or I go and sit outside and come back when he is quiet." (JN, age21, Kariobangi)

"Before I joined this group, I was so depressed; I used to be an angry person, my anger was so much near, even if someone wrongs me where we live then I carry it into the house on the kids and even on the husband; but since I came here, I have changed." (LA, age19, Kariobangi)

"- - at the moment I am stress-free and I just know how I can handle it; I sleep and wake up when I have forgotten those things but I normally thank God because I have never had stress." (RJ, age23, Kangemi) 
CHWs understanding of IPT-G intervention

\section{IPT themes Quotations}

Addresses loss "Me too it has helped me. Now that I can- I used to see a pregnant woman and I and grief for take another route that I don't want to meet, there where children are I could not go, CHWs but now I even carry your kids so it has helped me that's why you can see how strong I am."(LN,age 34,CHA,Kangemi)

Empowered PPA to live a better life
"It has been a nice thing, every time I see you. I normally get impressed and just smile because at least there is progress in our lives, we are not the same as the way we used to be okay?" (EO, age24, Kariobangi)

"I think that will help a lot because you see for the young girls you might find that when they do HIV test the husband is negative and the lady is positive so you see the girl gets stressed because she is harassed by the husband "where did you get the virus?" And whatever, it will help a lot [Silence]." (JA,age 24,Kangemi)
Building capacity and acknowledging the team
"Follow-up of that client, you have done IPT for this client you have done termination session; you have referred that client from facility to the community, who will do that follow-up? The community health workers. They are the linkage between the facility and the community and community to the facility." (LN,age 34,Kangemi)

Third IPT session is when disclosure happens

IPT Impact in the community

Group strengthens cohesion and empowers
"- -yes, they exist; when we started, we had a challenge because one we had not been trained, we had a challenge but we reached where we reached. I can say that even those girls when we start with them there are usually problems but the good thing is that mid-way they pick and can listen to you and sessions go well." (JA,age 24,Kangemi)

"In fact we always talk about that group wherever I go and maybe I meet a partner I always talk about that group, that's why I am saying I am still looking for a partner to support them, I always talk about it because we felt that we changed them and we wouldn't like them to get lost on the way, we would love them to come back and help the others." (LN,age 34,Kangemi)

"I think there is a time when we began IPT, those girls most of them were locking themselves in the house.... but now after the sessions in Kariobangi, we realized that they went back to work. Most of them have gone back to work, some other have started businesses, MA got a job and also has a business, EL has a business. So, people have gone back to work, there is SA has gone back to work; people are going back to work, people have started businesses but for one or two we are still following." (EO, age24, Kariobangi)

"She (PPA) realizes that she is not the only one and that they are several, don't you even see that the first thing they were accepting so much whenever she hears that this one is also like me, even this one and the other one so she feels that 'we are many." (NG,age 43,Kangemi)

"It used to help them to unwind because maybe somebody has an issue and feels like 'maybe it is only me who has this issue' so when she finds somebody in the group who says almost like similar to hers then she also opens her heart and speaks." (EO, age24, Kariobangi)

\section{Figures}




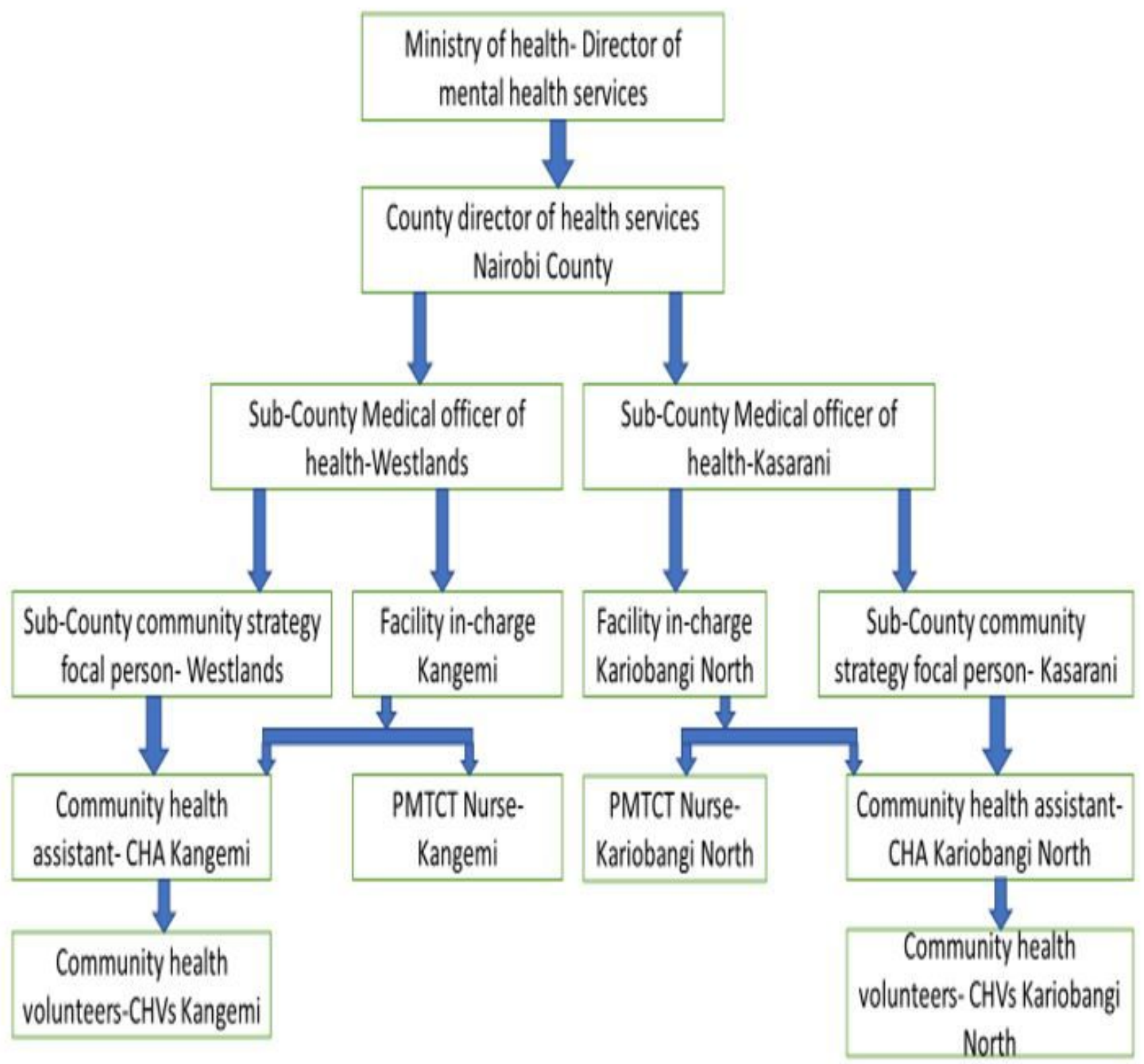

Figure 1

Collaborative structure for IPT implementation 